\title{
The Evolutionary Dynamics in the Research on Aflatoxins During the 2001-2010 Decade
}

\author{
Martín G. Theumer and Héctor R. Rubinstein \\ Centro de Investigaciones en Bioquímica Clínica e Inmunología (CIBICI), CONICET, \\ Departamento de Bioquímica Clínica, Facultad de Ciencias Químicas, \\ Universidad Nacional de Córdoba, \\ Argentina
}

\section{Introduction}

The interest on aflatoxins began in the late fifties and the early sixties, after more than 100 000 young turkeys' deaths were registered in the course of a few months in 1960 on poultry farms in England. Since the deaths were caused by an apparently new disease, it was termed "Turkey X disease". Shortly after, it was observed that the disease also affected ducklings and young pheasants with high rates of mortalities. The disease was initially suspected to be induced by toxins of fungal origin, and later was proved to be caused by aflatoxins, fungal secondary metabolites synthesized by toxigenic stocks of Aspergillus spp. This discovery has led to a growing awareness of the potential hazards of these substances as potential inducers of illnesses and even death in humans and other mammals (Kensler et al., 2011). Thus, the "Turkey X disease" outbreak is widely considered as the initial step in the era of the aflatoxins research.

The genus Aspergillus is an extremely common contaminant in stored products in tropical and subtropical regions; mainly grains, nuts and spices, and several Aspergillus species are frequently involved in its decomposition. These molds, and consequently the food contamination with mycotoxins that they synthesize, are ubiquitous in warm regions. Despite this, because the cold-climate countries import grain of geographical areas with tropical and subtropical climates, aflatoxins have gained importance worldwide. Moreover, nowadays the technological processes of food production fail to completely eliminate aflatoxins and therefore are part of food for humans and farm animals, thus favoring the diet-mediated intake of aflatoxins (Park, 2002).

The scientific literature on aflatoxins includes more than 8000 research articles, and the toxicological data regarding these compounds led to the International Agency for Research on Cancer to classify 1993 the naturally occurring aflatoxins as Group 1 (carcinogenic to humans), and the aflatoxin M1 (AFM1, an oxidative metabolic product of AFB1) as Group 2B (possibly carcinogenic to humans) (IARC, 1993).

In this chapter it is attempted to describe somehow the information generated in the aflatoxins field in the past decade on the basis of an exhaustive categorization of the publications retrieved by entering the keyword "aflatoxin" in the PubMed search engine 
(http://www.ncbi.nlm.nih.gov/sites/entrez?db=pubmed) of the United States National Library of Medicine web page, a database of biomedical literature widely used around the world. The initial searching criteria included all the articles published (print or electronic) between 2001/01/01 and 2010/12/31.

\section{Quantitative characterization of the research on aflatoxins through the 2001-2010 period}

\subsection{Number of publications}

Two thousands two hundreds and six results were retrieved by inserting the searching criteria specified above. These results were then further classified according to the year of publication (print or electronic), in order to evaluate the behavior of the research on the aflatoxins area throughout the decade. The figure 1 shows the evolution of the number of annual contributions.

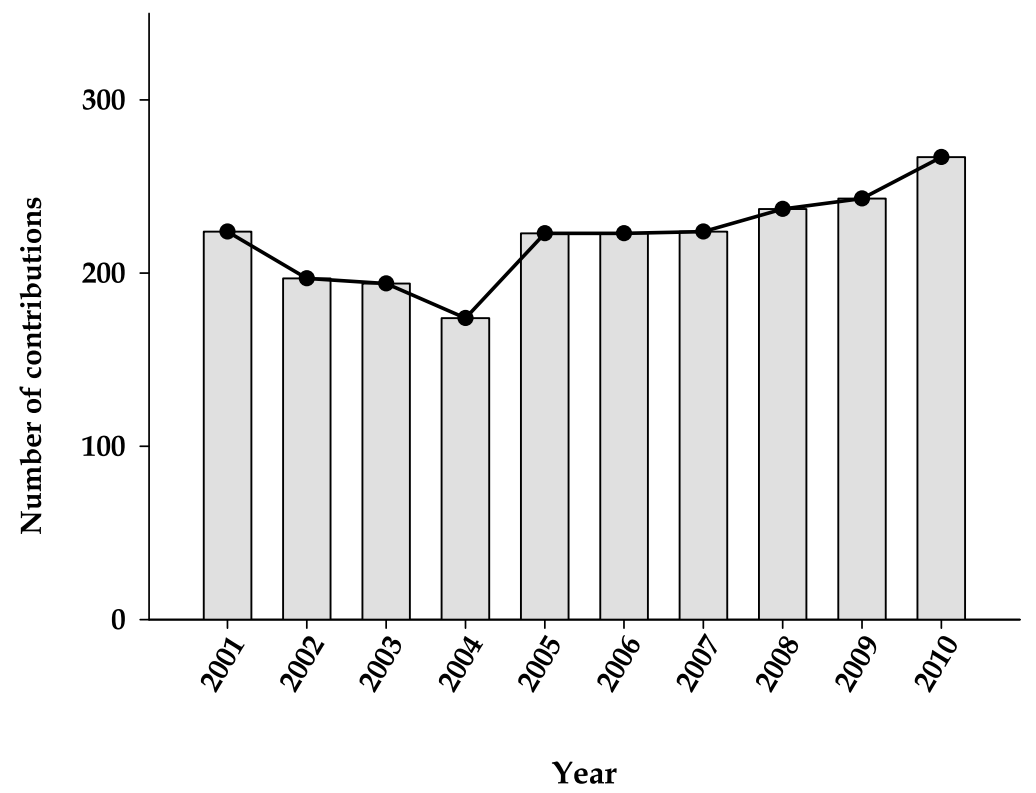

Fig. 1 . The behavior in the research on aflatoxins in the 2001-2010 decade, assessed by the number of publications by year.

The average number of contributions in the full period was 220 articles by year. Assessed by the number of annual publications, the research on the aflatoxins field decreased annually from years 2001 through 2004; however this tendency was reverted according to the number of contributions registered in 2005, when the interest in the aflatoxins research increased till to the end of the decade, with 267 contributions registered in 2010. 


\subsection{Type of articles}

The PubMed search engine also offers the possibility of filtering the requested information according to the type of contribution. Thus the searching results may include only clinical trials (phases I to IV), letters, original or corrected and republished journal articles, reviews, case reports, or congresses, for instance. This tool allows a fast characterization of the type of contribution on a specific issue. With regards to the specific field of the aflatoxins, the main publication type was original journal articles, as depicted in figure 2. The number of reviews was fluctuating in the 2001-2010 decade, and the number of journal articles published in the period showed a similar behavior to that of the total annual contributions.

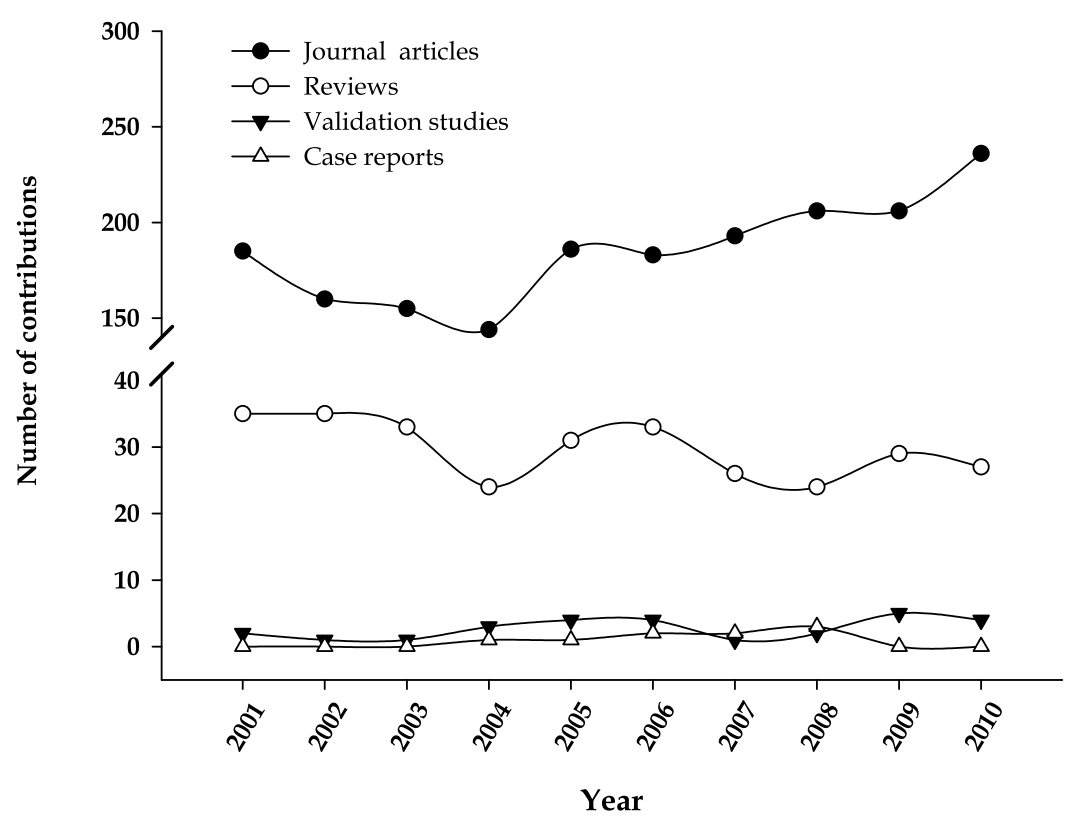

Fig. 2. The behavior in the research on aflatoxins in the 2001-2010 decade, assessed by the annual number of every main type of contribution.

The case reports are of special interest in mycotoxicology, since they may provide evidence for the linking of symptoms with diseases induced by fungal metabolites, or even may introduce new insights on the possible mechanisms of pathogenesis occurring in the natural poisonings with fungal toxins, for instance.

A total of 317 cases of acute aflatoxicosis were reported in Kenya by 20 July 2004, with a case fatality rate of $39 \%$. The 2004 outbreak resulted from widespread aflatoxin contamination of locally grown maize, which occurred during storage of the maize under damp conditions (Probst et al., 2007).

Mwanda and co-workers (2005) reported a 17-year-old schoolboy case of aflatoxicosis, highlighting the salient clinical findings in order to increase the index of suspicion, enhance early diagnosis and improve management of such cases. 
Case reports of probable aflatoxicosis in animals were also informed in 2004 and 2006. Osman et. al (2004) reported the death of twenty young female adult one-humped racing camels (Camelus dromedarius) kept in camps scattered outside Al Ain city and aged between 3- and 6-years-old, after a short clinical illness. On the other hand, in the USA more than 100 dogs apparently died as a result of the toxic effects of contaminated products, as it was suggested by medical history, clinical signs, progression of disease, and necropsy findings (Stenske et al., 2006).

Abstracts of Congresses such as the 3rd Fungal Genomics, 4th Fumonisin, and 16th Aflatoxin Elimination Workshops, 2003, Savannah, Georgia, USA; the Workshop on Aflatoxin and fumonisin elimination and fungal genomics, 2002, San Antonio, Texas, USA; and the Aflatoxin/Fumonisin Elimination and Fungal Genomics Workshops, 2001, Phoenix, Arizona, USA; were also published in the 2001-2010 decade.

\subsection{Main contributors}

A further analysis of journal articles and reviews retrieved by the PubMed search engine was carried out in order to determine the countries with a mayor contribution to the aflatoxins research field, and the results are depicted in figs. 3 and 4 .

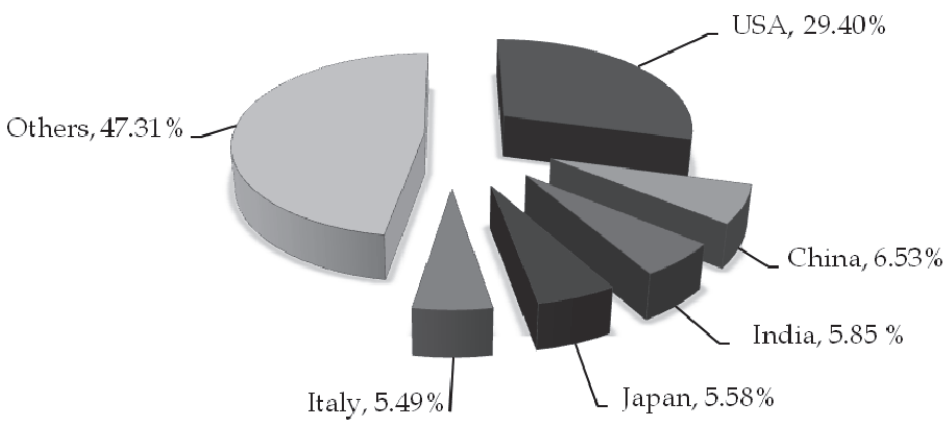

Fig. 3. Main contributor countries in the aflatoxins research, according to the number of articles published in the 2001-2010 decade.

According to the information provided by PubMed, the contributions in the research field of aflatoxins in the 2001-2010 decade were carried out in the following countries, alphabetically listed: Albania, Algeria, Argentina, Australia, Austria, Bangladesh, Belgium, Benin, Botswana, Brazil, Brunei, Bulgaria, Burundi, Cameroon, Canada, China, Colombia, Croatia, Cuba, Czech Republic, Denmark, Ecuador, Egypt, Ethiopia, Finland, France, The Gambia, Germany, Ghana, Greece, Hong Kong, Hungary, India, Indonesia, Iran, Iraq, Ireland, Israel, Italy, Japan, Kenya, North Korea, South Korea, Kuwait, Lebanon, Malawi, Malaysia, Mexico, Morocco, Nepal, Netherlands, New Zealand, Nigeria, Norway, Oman, Pakistan, Philippines, Poland, Portugal, Qatar, Romania, Russia, Samoa, Saudi Arabia, Serbia and Montenegro, Sierra Leone, Slovakia, Slovenia, South Africa, Spain, Sri Lanka, Sudan, Sweden, Switzerland, Taiwan, Tanzania, Thailand, Trinidad and Tobago, Tunisia, Turkey, Uganda, Ukraine, United Arab Emirates, United Kingdom, United States, Venezuela, Vietnam, Zambia. 

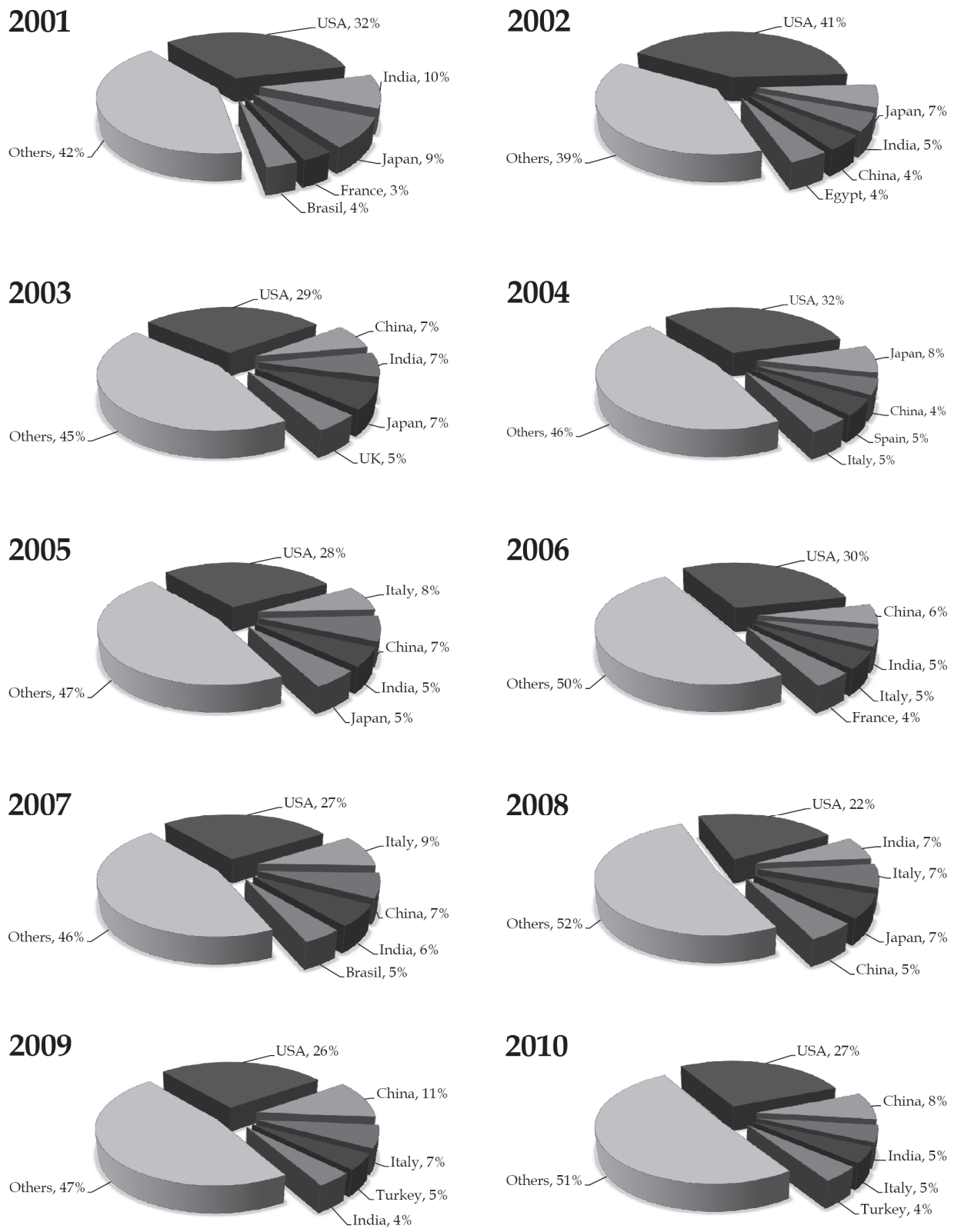

Fig. 4. The dynamic of the five main contributor countries in the aflatoxins research, according to the number of articles published by year in the 2001-2010 decade. 
The United States of America did the main contribution of original journal articles and reviews published in the aflatoxins research field in the whole period (fig. 3), which was related to highest annual contributions of this country from 2001 to 2010 (fig. 4). China, India, Japan and Italy were also quantitatively important contributors in the full period, with 6.53, 5.85, 5.58 and $5.49 \%$ of the total publications, respectively. These five countries contributed with more than a half of the articles related to aflatoxins within the decade. Detailed information on the top-five countries with the highest annual number of publications is shown in fig. 4 .

\section{Qualitative characterization of the research on aflatoxins through the 2001-2010 period}

\subsection{General overview}

The articles related to aflatoxins in the 2001-2010 decade were further classified qualitatively according to the focusing of the work into the following five main sub-areas of interest:

i. those oriented in the study of the plants commonly infected by aflatoxin-producing Aspergillus spp.;

ii. those where the main objective was to elucidate some issue related to the fungal physiology and its relationship with the environment;

iii. those where the interest was in the strategies for preservation and prevention of food contamination with aflatoxins;

iv. those focused in the elucidation of the physiological and biochemical disturbances associated with the exposure of cells/organisms to the aflatoxins, and the potential exogenous interventions to prevent them;

v. those concerning to the analytical methods commonly applied to detect and quantify aflatoxins in commodities or its by-products, for instance.

The fig. 5 shows the percentage of articles focused in every sub-area mentioned above.

More than a half of the publications in the 2001-2010 decade were oriented on topics related to the toxicology of aflatoxins. The same percentage of publications was focused in the fungal physiology and its relationship with the environment, and in the strategies for preservation and prevention of food contamination with aflatoxins. The minor proportion of the total contributions were concerning to the plants commonly infected by aflatoxinproducing Aspergillus spp.

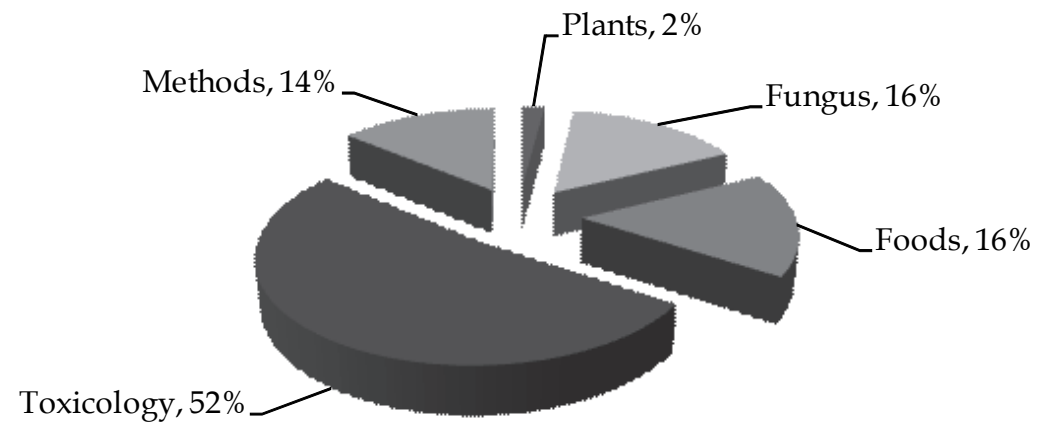

Fig. 5. Distribution of the total contributions in the decade into the main five focusing subareas in the research on aflatoxins. 
The same classification of the articles into the five sub-areas of interest was carried out in order to identify possible inter-annuals variations in the percentages of articles in every subarea. The results of this categorization are shown in the table 1.

\begin{tabular}{|c|c|c|c|c|c|}
\hline \multirow{2}{*}{ Year } & \multicolumn{5}{|c|}{ Sub-area of interest } \\
\hline & Plants & Fungi & Food & Toxicology & Methods \\
\hline 2001 & 3,6 & 10,0 & 15,9 & 58,2 & 12,3 \\
\hline 2002 & 2,5 & 13,2 & 18,3 & 57,9 & 8,1 \\
\hline 2003 & 0,5 & 13,4 & 16,0 & 62,9 & 7,2 \\
\hline 2004 & 1,7 & 19,1 & 12,7 & 56,1 & 10,4 \\
\hline 2005 & 1,9 & 17,2 & 17,6 & 51,1 & 12,2 \\
\hline 2006 & 3,3 & 14,0 & 17,6 & 52,0 & 13,1 \\
\hline 2007 & 1,8 & 21,0 & 15,6 & 42,4 & 19,2 \\
\hline 2008 & 1,3 & 18,6 & 17,7 & 48,9 & 13,5 \\
\hline 2009 & 1,2 & 18,2 & 14,9 & 43,0 & 22,7 \\
\hline 2010 & 1,9 & 12,5 & 17,4 & 50,8 & 17,4 \\
\hline
\end{tabular}

Table 1. Annual distribution of the contributions focusing into the main five sub-areas of interest in the research on aflatoxins.

The data are expressed as percentages of the total number of publications in the specified year.

The outstanding finding of this classification was the increasing proportion of the publicationsin the second part of the decade focusing in different aspects of the analytical methods. This could be related at least in part, to the increasing demand of new methods to detect simultaneously co-contamination of foods with several micotoxins, which also should be ideally feasible of applying to different matrices.

\subsection{Approaches in the articles regarding to plants}

Most of the work carried out in this sub-area aimed to pinpoint the biochemical basis of the susceptibility or resistance of plants to their infection with aflatoxin-producing fungus, and its subsequent contamination with this mycotoxin. Some examples of the advances in this area are mentioned below.

Baker et al. (2009a) used a proteomic approach in order to identify proteins that may be associated with the resistance of maize to the fungus. The authors identified a higher expression of a protein (ZmCORp) in maize resistant to A. flavus infection. The fungistatic activity exhibited by this protein was related with its inhibitory effect on the conidia germination and mycelia growth, concluding that ZmCORp may play an important role in enhancing kernel resistance to A. flavus infection and aflatoxin accumulation.

Trypsin inhibitors may also play a role in the susceptibility/resistance of maize to Aspergillus spp. infection. Baker et al. (2009b) observed that an overexpressed trypsin inhibitor reduced the germination of conidia as well as the mycelia growth from several maize pathogens, although the effect of this trypsin inhibitor on fungal growth was weaker than the previously reported for other trypsin inhibitors.

A proteomic approach performed by Chen and co-workers (2006) led to the identification of a pathogenesis-related protein (PR-10) which is expressed fivefold higher in maize resistant lines. It was also observed that the expression of this protein was induced upon A. flavus infection in a resistant but not in a susceptible genotype, thus suggesting the participation of this protein in kernel resistance to the infection by A. flavus. 
In a recent contribution, Gao and collaborators (2009) studied the potential interference of plant-derived oxylipins (a set of substances produced by the oxidation of polyunsaturated fatty acids by plant and fungal lipoxygenases) in the fungal development and in the secondary metabolism. The authors found contrasting results with different fungal pathogens, suggesting that the modulation of the plant-pathogen interactions are pathogen specific.

A novel PLD gene, encoding a putative phospholipase D, was identified in Arachis hypogea by $\mathrm{Gu}$ et al. (2006). The authors concluded that this PLD may be involved in drought sensitivity and tolerance response, and they also suggest the study of the PLD gene expression as a tool in germplasm screening for drought tolerance.

\subsection{Approaches in the articles regarding to fungus}

Several aspects were evaluated with regards to the fungi involved in the aflatoxins biosynthesis, including the molecular characterization of isolates in order to elucidate their phylogenetic relationships, the fungal biology and the genetic regulation leading to the mycotoxins production, the biochemical basis underlying the fungal reproduction, for instance. According to the publications registered in the 2001-2010 decade, much of the researchers' attention was on the identification of physical, chemical or biological conditions that ultimately reduce the fungal-induced food alterations and their contamination with aflatoxins. A wide spectrum of physical, chemical and biological agents was tested in attempts to solve such problems.

The essential oils from plants are complex mixtures of substances that in some cases exert strong biological activities against microorganisms. This property attracts the attention of researchers looking for new strategies of chemoprevention of the food contamination with mycotoxins.

Gandomi et al. (2010) tested the effects of Zataria multiflora Boiss. essential oil (EO) on A. flavus. The EO suppressed the size of colonies as well as the fungal esporulation. Electronic microscopy revealed morphological alterations ranging from loss of turgidity and uniformity of mycelia at low concentrations of EO to evident destruction of the hyphae at higher concentration of EO, mechanisms that could be involved in the fungal growth and in the biosynthesis of aflatoxins.

On the other hand, nine different oils were evaluated by Juglal and Govinden (2002) on the growth of A. parasiticus and Fusarium moniliforme. The highest growth inhibitory activity was found when clove oil (eugenol) was used, followed by cinnamon (cinnamic aldehyde), oregano (thymol and carvacol) and mace oils (myristin). Neem and eucalyptus oil (cineole) did not affect the fungal growth. Then, commonly occurring mycotoxigenic fungi could be controlled with clove oil (eugenol).

In other study, Kumar et al. (2007) observed that the EO extracted from the leaves of Chenopodium ambrosioides Linn. completely inhibited the mycelial growth and the aflatoxin synthesis, also exerting a broad fungitoxic spectrum against several toxigenic and nontoxigenic funguses.

Reverberi and co-workers (2005) studied the mechanisms underlying the aflatoxininhibiting effect of the Lentinula edodes culture filtrates. The authors reported that L. edodes lyophilised filtrates stimulate $A$. parasiticus anti-oxidant enzymes (superoxide dismutase, catalase, glutathione peroxidase) and aflatoxin inhibition was better correlated with betaglucan content than with anti-oxidant activity of the filtrates.

Several studies were performed with chemical substances purified from different sources. For instance, Cleveland et al. (2009) studied the effects of volatile compunds (including 
aldehydes, alcohols, ketones, and furans) produced upon exposure of soybean homogenates to lipase, on the A. flavus growth and aflatoxin production. They found that aldehydes inhibited up to $100 \%$ of the observed fungal growth and AFB1 production.

Goncalez and co-workers (2001) studied the effects of four biflavonoids isolated from Ouratea species on the A. flavus development and production of aflatoxins. These authors observed that the four biflavonoids showed inhibitory activity on aflatoxin B1 and B2 production, without alterations in the mycelial growth.

Analytical and industrial grade food additives effects on toxigenic Aspergillus were also tested, in order to identify a potential use as preservatives in foods. Passone et al. (2007) assayed the effects of three-food grade antioxidants: butylated hydroxyanisole (BHA), butylated hydroxytoluene (BHT) and propyl paraben (PP) to prove their fungitoxic effect on Aspergillus section Flavi strains. The authors concluded that idustrial grade antioxidant mixtures could be used for controlling the growth of mycotoxigenic species.

The biological control is a promising field to solve, at least in part, the problem of food contamination with aflatoxins. Several microorganisms could be use for this purpose, including bacteria and fungus.

Kong et al. (2010) evaluated a strain of marine Bacillus with regards to its activity in reducing postharvest decay of peanut kernels caused by A. flavus, and demonstrated that this marine bacterium could be used as a biocontrol agent against postharvest fungal disease.

Other bacteria such as Bacillus subtilis (Mohammadipour et al., 2009), isolations from almond flowers and mature nut fruits (Palumbo et al., 2006), and the Lactobacillus plantarum ATCC 8014 (Xu et al., 2003) were evaluated for their potential biocontrolling activities against aflatoxin-producing Aspergillus.

Studies with nontoxigenic strains of $A$. flavus and $A$. parasiticus separately and in combination were also conducted to determine the efficacy for reducing aflatoxin contamination in corn (Dorner, 2009) and peanuts (Dorner \& Horn, 2007). Whereas the results of some of these experiments indicated that the treatment with nontoxigenic $A$. flavus strains could be more effective than with the A. parasiticus strains, others results were inconclusive.

Penna \& Etcheverry (2006) observed that the interaction of Kluyveromyces spp. with Aspergillus aflatoxigenic strains induced changes on conidia germination, mycelial growth and aflatoxin B1 accumulation.

Since biological control can potentially have positive and negative effects on biodiversity, additional efforts are needed to clearly determine a minimum impact on nature by the introduction of such biological control strategies.

\subsection{Approaches in the articles regarding to foods}

Most of the articles classified within this category were surveys on the mycoflora and contamination of foods with aflatoxins. The fungal and aflatoxins contamination was reported in rice in Turkey (Aydin et al., 2010); in maize from south-western Nigeria (Bankole \& Mabekoje, 2004), Brazil (Rocha et al., 2009) and northern Italy (Pietri et al., 2004); in domestic and imported beers in Canada (Mably et al., 2005); and in peanuts in the Cote d'Ivoire (Sangare-Tigori et al., 2006), between others.

Since contamination of grains with mycotoxins is not efficiently eliminated by most of the food processing operations such as sorting, trimming, cleaning, milling, brewing, cooking, baking, frying, roasting, canning, flaking, alkaline cooking, nixtamalization, and extrusion; 
the fungal toxins are commonly found in grain by-products. Thus, the design of new technological food-processing methods that completely eliminate the mycotoxins is a field of growing interest for researchers worldwide.

Castells et al. (2008) studied the distribution of aflatoxins in various corn processed fractions during industrial cornflake processing. These authors observed that the application of dry milling of corn led to a heterogeneous distribution of the two groups of mycotoxins in the different parts of the grain, with increased levels in fractions processed from outer layers (animal feed flour and corn flour) and decreased levels in fractions processed from inner portions, such as corn meal and flaking grits.

The changes in concentration of aflatoxin M1 during manufacture of skim milk powder were assessed by Deveci \& Sezgin (2006) in cow's milk contaminated artificially with aflatoxin M1 (AFM1) at two different levels. Pasteurization, concentration, and spray drying reduced the AFM1 contents with efficiencies dependant on the contamination levels.

Park \& Kim (2006) studied the effect of pressure cooking on aflatoxin residues in polished rice. They found aflatoxin losses of $78-88 \%$ after pressure cooking, which correlated with the reduction of aflatoxin-induced mutagenic potential.

Interestingly, it was recently showed that raw material contamination with aflatoxins substantially affected the course of subsequent fermentation phases of maize mashes, influencing on characteristic factors such as alcohol concentration, productivity, yield and energy (Klosowski et al., 2010), and altering the composition of alcoholic fermentation volatile by-products in raw spirits (Klosowski \& Mikulski, 2010).

Notwithstanding the development of new technological strategies tending to reduce the food contamination with aflatoxins; the possible formation of mycotoxin degradation products (even more toxic that the mycotoxin itself), during the application of such technologies should be considered in all cases. Most of the food processes have variable effects on mycotoxins, with those that utilize the highest temperatures having greatest effects.

Physical, chemical and biological methods of decontamination of aflatoxin-contaminated materials are another strategy feasible of application to avoid the toxicological effects of aflatoxins in human beings and in animals. Frequently, the physical reduction of the mycotoxin contents is achieved by the mechanical removal of highly contaminated fractions. Aly \& Hathout (2011) suggested that the manufacture of hydrolyzed vegetable protein is a suitable method for decontamination of aflatoxin in highly contaminated grains, especially gluten fractions. This was concluded by the application of hydrochloric acid to aflatoxin B1 contaminated corn gluten.

Enzymes of diverse origins may also be a useful tool to reduce the aflatoxin contamination of different matrices, as it was suggested by Wang et al. (2011). In line with these observations, microorganisms may have advantages with respect to the use of a purified enzyme, since they provide a subset of metabolic pathways that potentially could reduce the aflatoxins levels (Guan et al., 2010).

\subsection{Approaches in the articles regarding to the toxicology of aflatoxins}

The determination of quantitative or qualitative value of risk related to the exposure of population to aflatoxins is a major concern, and is currently under evaluation in different geographic areas. Sugita-Konishi and co-workers (2010) evaluated the risk of exposure to aflatoxin B1 in Japan on the basis of the contamination of 24 foods from a 3-year retail market survey and data available on the food consumption by the population studied. 
Probabilistic approaches were used to estimate the aflatoxin B1 intake and the potential risk of cancer. The authors concluded that the current dietary intake of aflatoxin B1 in Japan has no appreciable effect on health.

The main etiology of hepatocellular carcinoma (HCC) is chronic infection with hepatitis B and hepatitis $\mathrm{C}$ viruses. However, other important factors such as obesity, diabetes, nonalcoholic steatohepatitis and dietary exposures to food toxins like aflatoxins, were linked with the development of this disease. Emerging evidence suggests that the etiology of many cases of HCC is in fact multifactorial. A clear relationship between the exposure to high levels of aflatoxins and the prevalence of HCC was identified in several geographic areas; however the precise aflatoxin-virus interaction in the induction of this disease remains unclear. The current knowledge concerning the participation of aflatoxins in the induction of HCC was recently reviewed by Sanyal et al. (2010) and Whittaker et al. (2010).

Biomarkers are currently used in the aflatoxins exposure assessment. They are classified as biomarkers of exposure (generally the aflatoxins itself or any of its metabolites, that can be measured in the body or after excretion from the body), effect (all the quantifiable changes that persists in an individual, which indicates the exposure to aflatoxins and may indicate a resulting health effect), and susceptibility (includes all natural characteristics of an organism that make it more susceptible to the effects of aflatoxins exposure).

Johnson et al. (2010) studied the levels of biomarkers of exposure (serum AFB1-lysine adduct and urinary AFM1) in order to assess the aflatoxins exposure in a community with elevated incidence of hepatocellular carcinoma. The results of this survey suggest that the incidence and level of AF exposure were less than those observed in a high-risk population. Theumer et al. (2010) studied the changes in some biomarkers of effect by the co-exposure of spleen mononuclear cells to a mixture of aflatoxin B1 and fumonisins, and concluded that a possible protective effect of the fumonisins-AFB1 mixtures may exist with regards to the genotoxicity induced individually by the toxins.

It was suggested that the CYP3A5 polymorphism found in the population of The Gambia, wich is associated with increased levels of the mutagenic AFB1-exo-8,9-epoxide particularly in individuals with low CYP3A4, may modulate individual risk of HCC (Wojnowski et al., 2004), and thus could be potentially used as a biomarker of susceptibility to aflatoxins.

Metabonomics and proteomics are promising approaches to elucidate the biochemical perturbations of metabolism caused by aflatoxins. An overview of biochemical consequences of AFB1 exposure and comprehensive insights into the metabolic aspects of AFB1-induced hepatotoxicity in rats was reported by Zhang et al. (2011), who studied the AFB1-induced metabonomic changes in multiple biological matrices (plasma, urine, and liver) of rats to understand the mammalian systems responses to aflatoxin B1 exposure. Li and co-workers (2008) performed a proteome analysis of aflatoxin B1-induced hepatocarcinogenesis in tree shrew (Tupaia belangeri chinensis) In order to explore the proteins responsible for HCC. They found a protein that differentially expressed in hepatocellular carcinoma (Peroxiredoxin II), with a probable important role in hepatocarcinogenesis, possibly through its function in regulating peroxidation and hereby providing a favorable microenvironment for cancer cell surviving and progressing.

Several studies were conducted in the 2001-2010 decade to characterize the impact of aflatoxins in the production performance of animals. For instance, Pandey \& Chauhan (2007) found alteration of several productive parameters, including weight gain, feed intake, feed gain ratio, age at sexual maturity, production and quality of eggs and retention of nutrients; in White Leghorn female chicks exposed to different levels of aflatoxins. 
The toxicity of aflatoxins to the central nervous, digestive, renal, reproductive and immunological systems was evaluated in multiple experimental designs with microorganisms, cell lines and primary cells from laboratory animal exposed to aflatoxins. The immunotoxic effects of aflatoxins were studied by Theumer et al. (2003) in subchronic mycotoxicoses in Wistar rats poisoned with aflatoxin B1 alone and mixed with fumonisins. Essential oils from plants, a wide spectrum of chemical substances, and microorganisms were co-administered with the aflatoxins with the aim of identify possible protective effects against the toxicity of afatoxins. Sghaier et al. (2010) found antimutagenic effects of the essential oil extracted from the aerial parts of Teucrium ramosissimum against aflatoxin B1, in the bacterial reverse mutation assay in Salmonella typhimurium TA98, TA100, and TA1535. In a similar experimental system, Polivkova and co-workers (2010) observed antimutagenic effects of lycopene and tomato puree, wich was related with a significant reduction of DNA damage in mice cells assessed by the micronucleus test.

Probiotics microorganisms could be used in order to amelliorate the adverse effects of exposure to aflatoxins (Kabak et al., 2009), since it was suggested that whole microbiological cells or fractions of them could adsorb mycotoxins, including the aflatoxins.

\subsection{Approaches in the articles regarding to methodologies}

One of the leading advances in the 2001-2010 decade, concerning the analytical methodologies feasible of being applied in the field of aflatoxins, was the development of methods to quantify multiple mycotoxins including aflatoxins in several grains and byproducts. For instance, Zachariasova et al. (2010) developed and optimized a simple, high-throughput method for the control of 32 mycotoxins (Fusarium and Alternaria toxins, aflatoxins, ergot alkaloids, ochratoxins, and sterigmatocystin) in beer.

Studies aimed to compare the performance of analytical methods were conducted by diverse laboratories. Zhang \& Chen (2004) compared the post-column derivatization technique for the determination of aflatoxins B1, B2, G1 and G2 and the rapid procedure with fluorometric analysis for the determination of total aflatoxins, concluding that the later was not the suitable method for the determination of total aflatoxins in medicinal herbs and plant extracts.

Rahamani et al. (2010) described the method validation for quantitative analysis of aflatoxins, ochratoxin A and zearalenone in cereals using HPLC with fluorescence detector; and concluded that it is suitable for the simultaneous determination of aflatoxins, ochratoxin A and zearalenone in cereals and is suitable for routine analysis.

The potential pre-analytical sources of error in the quantification of aflatoxins in foods were also considered in the 2001-2010 decade. Gallo et al. (2010) highlighted the possibility of underestimating the food contamination with aflatoxins by inefficient extraction procedures in cattle feed containing adsorbents. Brera and co-workers (2010) emphasized the use of proper sampling methods throughout the agri-food chain when it comes to effectively detecting contaminants in foods and feeds.

\section{Acknowledgment}

This work was partially supported by grants from Secretaría de Ciencia y Técnica de la Universidad Nacional de Córdoba (SeCyT-UNC), Agencia Nacional de Ciencia y Tecnología grants PICT $2005 \mathrm{~N}^{\circ}$ 15-32256 and PICT $2010 \mathrm{~N}^{\circ}$ 1232, and Ministerio de Ciencia y Tecnología de la provincia de Córdoba grant 0279-005429/2006. Martin G. Theumer is career investigator of the National Research Council of Argentina (CONICET). 


\section{References}

Aly, S.E. \& Hathout, A.S. (2011). Fate of aflatoxin B(1) in contaminated corn gluten during acid hydrolysis. Journal of the Science of Food and Agriculture Vol. 91, No. 3, (Feb), pp. 421-427, ISSN 1097-0010 (Electronic), 0022-5142 (Linking)

Aydin, A., Aksu, H. \& Gunsen, U. (2010). Mycotoxin levels and incidence of mould in Turkish rice. Environ Monit Assess, (Sep 9), ISSN 1573-2959 (Electronic), 0167-6369 (Linking)

Baker, R.L., Brown, R.L., Chen, Z.Y., Cleveland, T.E. \& Fakhoury, A.M. (2009a). A maize lectin-like protein with antifungal activity against Aspergillus flavus. Journal of Food Protection Vol. 72, No. 1, (Jan), pp. 120-127, ISSN 0362-028X (Print), 0362-028X (Linking)

Baker, R.L., Brown, R.L., Chen, Z.Y., Cleveland, T.E. \& Fakhoury, A.M. (2009b). A maize trypsin inhibitor (ZmTIp) with limited activity against Aspergillus flavus. Journal of Food Protection Vol. 72, No. 1, (Jan), pp. 185-188, ISSN 0362-028X (Print), 0362-028X (Linking)

Bankole, S.A. \& Mabekoje, O.O. (2004). Occurrence of aflatoxins and fumonisins in preharvest maize from south-western Nigeria. Food Additives and Contaminants Vol. 21, No. 3, (Mar), pp. 251-255, ISSN 0265-203X (Print), 0265-203X (Linking)

Brera, C., De Santis, B., Prantera, E., Debegnach, F., Pannunzi, E., Fasano, F., Berdini, C., Slate, A.B., Miraglia, M. \& Whitaker, T.B. (2010). Effect of sample size in the evaluation of "in-field" sampling plans for aflatoxin $\mathrm{B}(1)$ determination in corn. Journal of Agricultural and Food Chemis ry Vol. 58, No. 15, (Aug 11), pp. 8481-8489, ISSN 1520-5118 (Electronic), 0021-8561 (Linking)

Castells, M., Marin, S., Sanchis, V. \& Ramos, A.J. (2008). Distribution of fumonisins and aflatoxins in corn fractions during industrial cornflake processing. International Journal of Food Microbiology Vol. 123, No. 1-2, (Mar 31), pp. 81-87, ISSN 0168-1605 (Print), 0168-1605 (Linking)

Cleveland, T.E., Carter-Wientjes, C.H., De Lucca, A.J. \& Boue, S.M. (2009). Effect of soybean volatile compounds on Aspergillus flavus growth and aflatoxin production. J Food Sci Vol. 74, No. 2, (Mar), pp. H83-87, ISSN 1750-3841 (Electronic), 0022-1147 (Linking)

Chen, Z.Y., Brown, R.L., Rajasekaran, K., Damann, K.E. \& Cleveland, T.E. (2006). Identification of a Maize Kernel Pathogenesis-Related Protein and Evidence for Its Involvement in Resistance to Aspergillus flavus Infection and Aflatoxin Production. Phytopathology Vol. 96, No. 1, (Jan), pp. 87-95, ISSN 0031-949X (Print), 0031-949X (Linking)

Deveci, O. \& Sezgin, E. (2006). Changes in concentration of aflatoxin M1 during manufacture and storage of skim milk powder. Journal of Food Protection Vol. 69, No. 3, (Mar), pp. 682-685, ISSN 0362-028X (Print), 0362-028X (Linking)

Dorner, J.W. (2009). Biological control of aflatoxin contamination in corn using a nontoxigenic strain of Aspergillus flavus. Journal of Food Protection Vol. 72, No. 4, (Apr), pp. 801-804, ISSN 0362-028X (Print), 0362-028X (Linking)

Dorner, J.W. \& Horn, B.W. (2007). Separate and combined applications of nontoxigenic Aspergillus flavus and A. parasiticus for biocontrol of aflatoxin in peanuts. 
Mycopathologia Vol. 163, No. 4, (Apr), pp. 215-223, ISSN 0301-486X (Print), 0301486X (Linking)

Gallo, A., Masoero, F., Bertuzzi, T., Piva, G. \& Pietri, A. (2010). Effect of the inclusion of adsorbents on aflatoxin B1 quantification in animal feedstuffs. Food Addit Contam Part A Chem Anal Control Expo Risk Assess Vol. 27, No. 1, (Jan), pp. 54-63, ISSN 19440057 (Electronic), 1944-0057 (Linking)

Gandomi, H., Misaghi, A., Akhondzadeh Basti, A., Hamedi, H. \& Ramezani Shirvani, Z. (2010). Effect of Zataria multiflora Boiss. essential oil on colony morphology and ultrastructure of Aspergillus flavus. Mycoses, (Oct 11), ISSN 1439-0507 (Electronic), 0933-7407 (Linking)

Gao, X., Brodhagen, M., Isakeit, T., Brown, S.H., Gobel, C., Betran, J., Feussner, I., Keller, N.P. \& Kolomiets, M.V. (2009). Inactivation of the lipoxygenase ZmLOX3 increases susceptibility of maize to Aspergillus spp. Molecular Plant-Microbe Interactions Vol. 22, No. 2, (Feb), pp. 222-231, ISSN 0894-0282 (Print), 0894-0282 (Linking)

Goncalez, E., Felicio, J.D. \& Pinto, M.M. (2001). Biflavonoids inhibit the production of aflatoxin by Aspergillus flavus. Brazilian Journal of Medical and Biological Research Vol. 34, No. 11, (Nov), pp. 1453-1456, ISSN 0100-879X (Print), 0100-879X (Linking)

Guan, S., Zhao, L., Ma, Q., Zhou, T., Wang, N., Hu, X. \& Ji, C. (2010). In Vitro Efficacy of Myxococcus fulvus ANSM068 to Biotransform Aflatoxin B(1). Int J Mol Sci Vol. 11, No. 10, pp. 4063-4079, ISSN 1422-0067 (Electronic), 1422-0067 (Linking)

Guo, B.Z., Xu, G., Cao, Y.G., Holbrook, C.C. \& Lynch, R.E. (2006). Identification and characterization of phospholipase $\mathrm{D}$ and its association with drought susceptibilities in peanut (Arachis hypogaea). Planta Vol. 223, No. 3, (Feb), pp. 512520, ISSN 0032-0935 (Print), 0032-0935 (Linking)

IARC, 1993. IARC Monographs on the evaluation of carcinogenic risks to humans., Some naturally occurring substances: Food items and constituents, heterocyclic aromatic amines and mycotoxins. Aflatoxins, International Agency for Research on Cancer, Lyon, pp. 249-395

Johnson, N.M., Qian, G., Xu, L., Tietze, D., Marroquin-Cardona, A., Robinson, A., Rodriguez, M., Kaufman, L., Cunningham, K., Wittmer, J., Guerra, F., Donnelly, K.C., Williams, J.H., Wang, J.S. \& Phillips, T.D. (2010). Aflatoxin and PAH exposure biomarkers in a U.S. population with a high incidence of hepatocellular carcinoma. Science of the Total Environment Vol. 408, No. 23, (Nov 1), pp. 6027-6031, ISSN 18791026 (Electronic), 0048-9697 (Linking)

Juglal, S., Govinden, R. \& Odhav, B. (2002). Spice oils for the control of co-occurring mycotoxin-producing fungi. Journal of Food Protection Vol. 65, No. 4, (Apr), pp. 683687, ISSN 0362-028X (Print), 0362-028X (Linking)

Kabak, B., Brandon, E.F., Var, I., Blokland, M. \& Sips, A.J. (2009). Effects of probiotic bacteria on the bioaccessibility of aflatoxin $\mathrm{B}(1)$ and ochratoxin $\mathrm{A}$ using an in vitro digestion model under fed conditions. Journal of Environmental Science and Health. Part B: Pesticides, Food Contaminants, and Agricultural Wastes Vol. 44, No. 5, (Jun), pp. 472480, ISSN 1532-4109 (Electronic), 0360-1234 (Linking) 
Kensler, T.W., Roebuck, B.D., Wogan, G.N. \& Groopman, J.D. (2011). Aflatoxin: a 50-year odyssey of mechanistic and translational toxicology. Toxicological Sciences Vol. 120 Suppl 1, (Mar), pp. S28-48, ISSN 1096-0929 (Electronic), 1096-0929 (Linking)

Klosowski, G. \& Mikulski, D. (2010). The effect of raw material contamination with mycotoxins on the composition of alcoholic fermentation volatile by-products in raw spirits. Bioresour Technol Vol. 101, No. 24, (Dec), pp. 9723-9727, ISSN 1873-2976 (Electronic), 0960-8524 (Linking)

Klosowski, G., Mikulski, D., Grajewski, J. \& Blajet-Kosicka, A. (2010). The influence of raw material contamination with mycotoxins on alcoholic fermentation indicators. Bioresour Technol Vol. 101, No. 9, (May), pp. 3147-3152, ISSN 1873-2976 (Electronic), 0960-8524 (Linking)

Kong, Q., Shan, S., Liu, Q., Wang, X. \& Yu, F. (2010). Biocontrol of Aspergillus flavus on peanut kernels by use of a strain of marine Bacillus megaterium. International Journal of Food Microbiology Vol. 139, No. 1-2, (Apr 30), pp. 31-35, ISSN 1879-3460 (Electronic), 0168-1605 (Linking)

Kumar, R., Mishra, A.K., Dubey, N.K. \& Tripathi, Y.B. (2007). Evaluation of Chenopodium ambrosioides oil as a potential source of antifungal, antiaflatoxigenic and antioxidant activity. International Journal of Food Microbiology Vol. 115, No. 2, (Apr 10), pp. 159-164, ISSN 0168-1605 (Print), 0168-1605 (Linking)

Li, Y., Qin, X., Cui, J., Dai, Z., Kang, X., Yue, H., Zhang, Y., Su, J., Cao, J., Ou, C., Yang, C., Duan, X. \& Liu, Y. (2008). Proteome analysis of aflatoxin B1-induced hepatocarcinogenesis in tree shrew (Tupaia belangeri chinensis) and functional identification of candidate protein peroxiredoxin II. Proteomics Vol. 8, No. 7, (Apr), pp. 1490-1501, ISSN 1615-9861 (Electronic), 1615-9853 (Linking)

Mably, M., Mankotia, M., Cavlovic, P., Tam, J., Wong, L., Pantazopoulos, P., Calway, P. \& Scott, P.M. (2005). Survey of aflatoxins in beer sold in Canada. Food Additives and Contaminants Vol. 22, No. 12, (Dec), pp. 1252-1257, ISSN 0265-203X (Print), 0265203X (Linking)

Mohammadipour, M., Mousivand, M., Salehi Jouzani, G. \& Abbasalizadeh, S. (2009). Molecular and biochemical characterization of Iranian surfactin-producing Bacillus subtilis isolates and evaluation of their biocontrol potential against Aspergillus flavus and Colletotrichum gloeosporioides. Canadian Journal of Microbiology Vol. 55, No. 4, (Apr), pp. 395-404, ISSN 0008-4166 (Print), 0008-4166 (Linking)

Mwanda, O.W., Otieno, C.F. \& Omonge, E. (2005). Acute aflatoxicosis: case report. East African Medical Journal Vol. 82, No. 6, (Jun), pp. 320-324, ISSN 0012-835X (Print), 0012-835X (Linking)

Osman, N., El-Sabban, F.F., Al Khawli, A. \& Mensah-Brown, E.P. (2004). Effect of foodstuff contamination by aflatoxin on the one-humped camel (Camelus dromedarius) in $\mathrm{Al}$ Ain, United Arab Emirates. Aust Vet J Vol. 82, No. 12, (Dec), pp. 759-761, ISSN 00050423 (Print), 0005-0423 (Linking)

Palumbo, J.D., Baker, J.L. \& Mahoney, N.E. (2006). Isolation of bacterial antagonists of Aspergillus flavus from almonds. Microbial Ecology Vol. 52, No. 1, (Jul), pp. 45-52, ISSN 0095-3628 (Print), 0095-3628 (Linking) 
Pandey, I. \& Chauhan, S.S. (2007). Studies on production performance and toxin residues in tissues and eggs of layer chickens fed on diets with various concentrations of aflatoxin AFB1. British Poultry Science Vol. 48, No. 6, (Dec), pp. 713-723, ISSN 14661799 (Electronic), 0007-1668 (Linking)

Park, D.L. (2002). Effect of processing on aflatoxin. Advances in Experimental Medicine and Biology Vol. 504, pp. 173-179, ISSN 0065-2598 (Print), 0065-2598 (Linking)

Park, J.W. \& Kim, Y.B. (2006). Effect of pressure cooking on aflatoxin B1 in rice. Journal of Agricultural and Food Chemis ry Vol. 54, No. 6, (Mar 22), pp. 2431-2435, ISSN 00218561 (Print), 0021-8561 (Linking)

Passone, M.A., Resnik, S. \& Etcheverry, M.G. (2007). Antiaflatoxigenic property of food grade antioxidants under different conditions of water activity in peanut grains. International Journal of Food Microbiology Vol. 118, No. 1, (Aug 15), pp. 8-14, ISSN 0168-1605 (Print), 0168-1605 (Linking)

Penna, M.L. \& Etcheverry, M. (2006). Impact on growth and aflatoxin B1 accumulation by Kluyveromyces isolates at different water activity conditions. Mycopathologia Vol. 162, No. 5, (Nov), pp. 347-353, ISSN 0301-486X (Print), 0301-486X (Linking)

Pietri, A., Bertuzzi, T., Pallaroni, L. \& Piva, G. (2004). Occurrence of mycotoxins and ergosterol in maize harvested over 5 years in Northern Italy. Food Additives and Contaminants Vol. 21, No. 5, (May), pp. 479-487, ISSN 0265-203X (Print), 0265-203X (Linking)

Polivkova, Z., Smerak, P., Demova, H. \& Houska, M. (2010). Antimutagenic effects of lycopene and tomato puree. J Med Food Vol. 13, No. 6, (Dec), pp. 1443-1450, ISSN 1557-7600 (Electronic), 1096-620X (Linking)

Probst, C., Njapau, H. \& Cotty, P.J. (2007). Outbreak of an acute aflatoxicosis in Kenya in 2004: identification of the causal agent. Applied and Environmental Microbiology Vol. 73, No. 8, (Apr), pp. 2762-2764, ISSN 0099-2240 (Print), 0099-2240 (Linking)

Rahmani, A., Jinap, S. \& Soleimany, F. (2010). Validation of the procedure for the simultaneous determination of aflatoxins ochratoxin A and zearalenone in cereals using HPLC-FLD. Food Addit Contam Part A Chem Anal Control Expo Risk Assess Vol. 27, No. 12, (Dec), pp. 1683-1693, ISSN 1944-0057 (Electronic), 1944-0057 (Linking)

Reverberi, M., Fabbri, A.A., Zjalic, S., Ricelli, A., Punelli, F. \& Fanelli, C. (2005). Antioxidant enzymes stimulation in Aspergillus parasiticus by Lentinula edodes inhibits aflatoxin production. Applied Microbiology and Biotechnology Vol. 69, No. 2, (Nov), pp. 207-215, ISSN 0175-7598 (Print), 0175-7598 (Linking)

Rocha, L.O., Nakai, V.K., Braghini, R., Reis, T.A., Kobashigawa, E. \& Correa, B. (2009). Mycoflora and co-occurrence of fumonisins and aflatoxins in freshly harvested corn in different regions of Brazil. Int J Mol Sci Vol. 10, No. 11, (Nov), pp. 5090-5103, ISSN 1422-0067 (Electronic), 1422-0067 (Linking)

Sangare-Tigori, B., Moukha, S., Kouadio, H.J., Betbeder, A.M., Dano, D.S. \& Creppy, E.E. (2006). Co-occurrence of aflatoxin B1, fumonisin B1, ochratoxin A and zearalenone in cereals and peanuts from Cote d'Ivoire. Food Additives and Contaminants Vol. 23, No. 10, (Oct), pp. 1000-1007, ISSN 0265-203X (Print), 0265-203X (Linking) 
Sanyal, A.J., Yoon, S.K. \& Lencioni, R. (2010). The etiology of hepatocellular carcinoma and consequences for treatment. The Oncologist Vol. 15 Suppl 4, pp. 14-22, ISSN 1549490X (Electronic), 1083-7159 (Linking)

Sghaier, M.B., Boubaker, J., Neffati, A., Limem, I., Skandrani, I., Bhouri, W., Bouhlel, I., Kilani, S., Chekir-Ghedira, L. \& Ghedira, K. (2010). Antimutagenic and antioxidant potentials of Teucrium ramosissimum essential oil. Chem Biodivers Vol. 7, No. 7, (Jul), pp. 1754-1763, ISSN 1612-1880 (Electronic), 1612-1872 (Linking)

Stenske, K.A., Smith, J.R., Newman, S.J., Newman, L.B. \& Kirk, C.A. (2006). Aflatoxicosis in dogs and dealing with suspected contaminated commercial foods. J Am Vet Med Assoc Vol. 228, No. 11, (Jun 1), pp. 1686-1691, ISSN 0003-1488 (Print), 0003-1488 (Linking)

Sugita-Konishi, Y., Sato, T., Saito, S., Nakajima, M., Tabata, S., Tanaka, T., Norizuki, H., Itoh, Y., Kai, S., Sugiyama, K., Kamata, Y., Yoshiike, N. \& Kumagai, S. (2010). Exposure to aflatoxins in Japan: risk assessment for aflatoxin B1. Food Addit Contam Part A Chem Anal Control Expo Risk Assess Vol. 27, No. 3, (Mar), pp. 365-372, ISSN 19440057 (Electronic), 1944-0057 (Linking)

Theumer, M.G., Canepa, M.C., Lopez, A.G., Mary, V.S., Dambolena, J.S. \& Rubinstein, H.R. (2010). Subchronic mycotoxicoses in Wistar rats: assessment of the in vivo and in vitro genotoxicity induced by fumonisins and aflatoxin $\mathrm{B}(1)$, and oxidative stress biomarkers status. Toxicology Vol. 268, No. 1-2, (Jan 31), pp. 104-110, ISSN 1879-3185 (Electronic), 0300-483X (Linking)

Theumer, M.G., Lopez, A.G., Masih, D.T., Chulze, S.N. \& Rubinstein, H.R. (2003). Immunobiological effects of AFB1 and AFB1-FB1 mixture in experimental subchronic mycotoxicoses in rats. Toxicology Vol. 186, No. 1-2, (Apr 15), pp. 159-170, ISSN 0300-483X (Print), 0300-483X (Linking)

Wang, J., Ogata, M., Hirai, H. \& Kawagishi, H. (2011). Detoxification of aflatoxin B1 by manganese peroxidase from the white-rot fungus Phanerochaete sordida YK-624. FEMS Microbiology Letters Vol. 314, No. 2, (Jan), pp. 164-169, ISSN 1574-6968 (Electronic), 0378-1097 (Linking)

Whittaker, S., Marais, R. \& Zhu, A.X. (2010). The role of signaling pathways in the development and treatment of hepatocellular carcinoma. Oncogene Vol. 29, No. 36, (Sep 9), pp. 4989-5005, ISSN 1476-5594 (Electronic), 0950-9232 (Linking)

Wojnowski, L., Turner, P.C., Pedersen, B., Hustert, E., Brockmoller, J., Mendy, M., Whittle, H.C., Kirk, G. \& Wild, C.P. (2004). Increased levels of aflatoxin-albumin adducts are associated with CYP3A5 polymorphisms in The Gambia, West Africa. Pharmacogenetics Vol. 14, No. 10, (Oct), pp. 691-700, ISSN 0960-314X (Print), 0960$314 X$ (Linking)

Xu, J., Wang, H., Ji, R. \& Luo, X. (2003). [Study on the effect of the growth and aflatoxin production by Aspergillus flavus parasiticus NRRL 2999 in the present of Lactobacillus plantarum ATCC 8014]. Wei Sheng Yan Jiu Vol. 32, No. 4, (Jul), pp. 334-338, ISSN 1000-8020 (Print), 1000-8020 (Linking)

Zachariasova, M., Cajka, T., Godula, M., Malachova, A., Veprikova, Z. \& Hajslova, J. (2010). Analysis of multiple mycotoxins in beer employing (ultra)-high-resolution mass 
spectrometry. Rapid Communications in Mass Spectrometry Vol. 24, No. 22, (Nov 30), pp. 3357-3367, ISSN 1097-0231 (Electronic), 0951-4198 (Linking)

Zhang, L., Ye, Y., An, Y., Tian, Y., Wang, Y. \& Tang, H. (2011). Systems responses of rats to aflatoxin B1 exposure revealed with metabonomic changes in multiple biological matrices. J Proteome Res Vol. 10, No. 2, (Feb 4), pp. 614-623, ISSN 1535-3907 (Electronic), 1535-3893 (Linking)

Zhang, X.H. \& Chen, J.M. (2004). [Comparison between the post-column derivatization with bromine by HPLC and the fluorometric analysis for determination of aflatoxins in medicinal herbs and plant extracts]. Yao Xue Xue Bao Vol. 39, No. 12, (Dec), pp. 9971000, ISSN 0513-4870 (Print), 0513-4870 (Linking) 


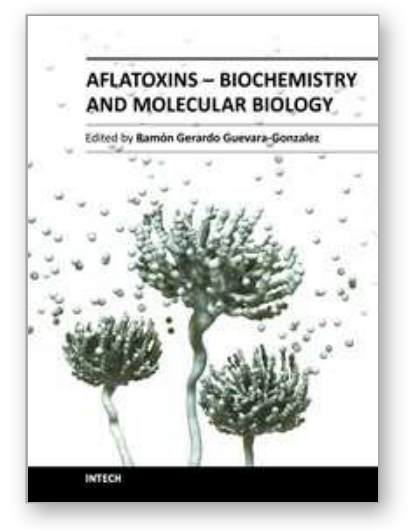

\author{
Aflatoxins - Biochemistry and Molecular Biology \\ Edited by Dr. Ramon G. Guevara-Gonzalez
}

ISBN 978-953-307-395-8

Hard cover, 468 pages

Publisher InTech

Published online 03, October, 2011

Published in print edition October, 2011

Aflatoxins â€" Biochemistry and Molecular Biology is a book that has been thought to present the most significant advances in these disciplines focused on the knowledge of such toxins. All authors, who supported the excellent work showed in every chapter of this book, are placed at the frontier of knowledge on this subject, thus, this book will be obligated reference to issue upon its publication. Finally, this book has been published in an attempt to present a written forum for researchers and teachers interested in the subject, having a current picture in this field of research about these interesting and intriguing toxins.

\title{
How to reference
}

In order to correctly reference this scholarly work, feel free to copy and paste the following:

Martin G. Theumer and Héctor R. Rubinstein (2011). The Evolutionary Dynamics in the Research on Aflatoxins During the 2001-2010 Decade, Aflatoxins - Biochemistry and Molecular Biology, Dr. Ramon G. GuevaraGonzalez (Ed.), ISBN: 978-953-307-395-8, InTech, Available from: http://www.intechopen.com/books/aflatoxins-biochemistry-and-molecular-biology/the-evolutionary-dynamics-inthe-research-on-aflatoxins-during-the-2001-2010-decade

\section{INTECH}

open science | open minds

\section{InTech Europe}

University Campus STeP Ri

Slavka Krautzeka 83/A

51000 Rijeka, Croatia

Phone: +385 (51) 770447

Fax: +385 (51) 686166

www.intechopen.com

\section{InTech China}

Unit 405, Office Block, Hotel Equatorial Shanghai

No.65, Yan An Road (West), Shanghai, 200040, China

中国上海市延安西路65号上海国际贵都大饭店办公楼405单元

Phone: +86-21-62489820

Fax: $+86-21-62489821$ 
(C) 2011 The Author(s). Licensee IntechOpen. This is an open access article distributed under the terms of the Creative Commons Attribution 3.0 License, which permits unrestricted use, distribution, and reproduction in any medium, provided the original work is properly cited. 